\title{
Funções Exponenciais: Uma Contextualização Através de Aplicações Cotidianas
}

\section{Exponential Functions: a Contextualization Through Everyday Applications}

\author{
Igor Alvarenga da Silva Nascimento \\ Universidade Federal do Estado do Rio de Janeiro -UNIRIO \\ igor.ime@gmail.com \\ Mário César Martins de Lima \\ Universidade Federal do Estado do Rio de Janeiro -UNIRIO \\ marinholc1@gmail.com
}

Resumo: A didática que envolve o ensino de modelos exponenciais se reveste de um caráter muito puro, sem conexão com a realidade do discente. O artigo apresenta algumas aplicações que podem ser utilizadas no ensino de funções exponenciais no Ensino Médio, tornando a assimilação dos conteúdos por parte do aluno uma atividade prazerosa e relacionada ao seu cotidiano. Ainda, pretende-se deixar uma sugestão de abordagem do conteúdo por meio de uma sequência didática simples de aulas, otimizando e buscando a correta compreensão dos tópicos pelos jovens, bem como despertando o interesse pelo assunto.

Palavras-chave: funções exponenciais; aplicações; curiosidades; modelos.

Abstract: The didacticism that involves the teaching of exponential models is of a very pure character, without connection with the reality of the student. The article presents some applications that can be used in the teaching of exponential functions in High School, making the assimilation of contents by the student a pleasant activity and related to their daily life. Still, it is intended to leave a suggestion to approach the content through a simple didactic sequence of classes, optimizing and seeking the correct understanding of the topics by young people, as well as arousing interest in the subject.

Key words: exponential functions; applications; curiosities; models.

\section{Introdução}

A motivação para o estudo dos modelos exponenciais reside na aplicabilidade de inúmeros fenômenos que se pode observar. Diante da observação, percebeu-se que a forma como a matéria é ministrada nas escolas de Ensino Médio não apresenta uma recepção adequada

pelos discentes. É tida como bastante abstrata e pura, fazendo com que o aluno, de forma geral, não perceba a importância do assunto para a sua formação como cidadão e para o seu futuro profissional.

Apesar da constatação dos métodos de ensino, os documentos educacionais já previam um ensino mais contextualizado, adequado às realidades do público-alvo. Corroborando, cita-se os Parâmetros Curriculares Nacionais (PCN) para o Ensino Médio [1], na área de Matemática:

Recebido em 30/09/2017 - Aceito em 30/10/2017

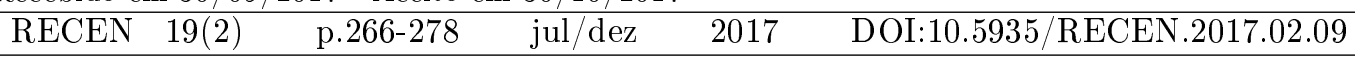


NASCIMENTO, I. A. S. e LIMA, M. C. M.

"A Matemática no Ensino Médio tem um valor formativo, que ajuda a estruturar o pensamento $e$ o raciocínio dedutivo, porém também desempenha um papel instrumental, pois é uma ferramenta que serve para a vida cotidiana e para muitas tarefas específicas em quase todas as atividades

humanas."

Assim, fica claro que é necessário abordar os conteúdos matemáticos de forma mais aplicada possível à realidade do discente. Caso contrário, corre-se o risco de que o aluno se desinteresse cada vez mais pelos assuntos ensinados, resultando em reprovações e ojeriza aos conteúdos.

Ainda, conforme os PCN [1]:

"De fato, não basta revermos a forma ou metodologia de ensino, se mantivermos o conhecimento matemático restrito à informação, com as definições e os exemplos, assim como a exercitação, ou seja, exercícios de aplicação ou fixação. Pois, se os conceitos são apresentados de forma fragmentada, mesmo que de forma completa e aprofundada, nada garante que o aluno estabeleça alguma significação para as ideias isoladas e desconectadas umas das outras. Acredita-se que o aluno sozinho seja capaz de construir as múltiplas relações entre os conceitos e formas de raciocínio envolvidas nos diversos conteúdos; no entanto, o fracasso escolar e as dificuldades dos alunos frente à Matemática mostram claramente que isso não é verdade."

Assim, combate-se o ensino puramente pragmático e totalmente desconexo da realidade que cerca o aluno. Deve-se buscar, incessantemente, as aplicações atinentes ao conteúdo ministrado, sempre que possível. Desta forma, possivelmente haverá uma recepção melhor do aluno aos ensinamentos transmitidos.

No ensino brasileiro, já está consagrada a preocupação com a contextualização e a interdisciplinaridade. Novamente, nos PCN [1], em sua página 43, tem-se:

"O critério central é o da contextualização e da interdisciplinaridade, ou seja, é o potencial de um tema permitir conexões entre diversos conceitos matemáticos e entre diferentes formas de pensamento matemático, ou, ainda, a relevância cultural do tema, tanto no que diz respeito às suas aplicações dentro ou fora da Matemática, como à sua importância histórica no desenvolvimento da própria ciência."

Tratando-se de funções exponenciais, é importante contextualizar o seu ensino. A modelagem deste tipo de função surgiu ante a necessidade de solucionar um problema ainda sem resposta. A modelagem da função afim já era conhecida, porém com o surgimento de uma nova demanda, houve a procura de um novo modelo teórico. Conforme Bassanezi [2], ressalta-se a importância:

"O objetivo fundamental da aplicação da matemática é de fato extrair a parte essencial da situação-problema e formalizá-la em um contexto abstrato onde o pensamento possa ser absorvido com uma extraordinária economia de linguagem. Desta forma, a matemática pode ser vista como um instrumento intelectual capaz de sintetizar ideias concebidas em situações empíricas que estão quase sempre camufladas num emaranhado de variáveis de menor importância."

Portanto, acredita-se que, através de uma adequada contextualização, se consiga atingir melhores resultados quanto à assimilação dos conteúdos. É importante ressaltar que, em nenhuma hipótese, se deseja deixar o formalismo matemático em detrimento da realidade do assunto. Ambos são importantes para a construção do saber do nosso aluno. O que se pretende evitar é o exagero de qualquer uma das ferramentas. Caberá ao docente, no momento adequado, formalizar os conceitos, fornecendo o embasamento necessário e oportuno, tendo em vista que é um dos objetivos do ensino da Matemática. 
Revista Ciências Exatas e Naturais, Vol.19, nº.2, Jul/Dez, 2017

Explicar a origem do assunto e o seu motivo de surgimento, através de exemplos, também podem ser ótimos caminhos para motivar o estudo da Matemática e, especificamente, de funções exponenciais. Um ótimo exemplo é a famosa história (porém pouco conhecida, infelizmente) de um rei persa que, ao perceber que o seu reino se encontrava entendiado com a rotina diária, recompensaria quem criasse algum jogo para entretenimento da corte.

A notícia, rapidamente, se espalhou por todo o domínio real, até que um dos súditos apresentou uma espécie de jogo de xadrez. Vale ressaltar que não se sabe ao certo se o jogo era inédito. Relatos afirmam que foi uma adaptação de um jogo de tabuleiro já experimentado pelos gregos.

O jogo de 32 peças e 64 casas quadradas com um dinâmica bem interessante. O rei ficou maravilhado e o passatempo foi um sucesso. Diante disso, mandou que chamassem o súdito imediatamente para uma conversa. Perguntou-lhe o que queria como recompensa, já que o objetivo havia sido atingido em sua plenitude. Ofereceu-lhe ouro, joias, posses e até um casamento com uma de suas filhas.

Porém, para a surpresa do governante, a resposta do súdito foi que queria grãos de arroz, distribuídos da seguinte forma: 1 grão na primeira casa, 2 na segunda, 4 na terceira, 8 na quarta e assim sucessivamente, sempre duplicando a quantidade de grãos da casa anterior, até que as 64 casas estivessem completas.

O rei, maravilhado e boquiaberto com a humildade do súdito, mandou que trouxessem imediatamente os grãos de arroz. Ao iniciar a empreitada, percebeu que todo o seu reino não possuía quantidade de grãos suficiente para arcar com o compromisso. Desesperado, mandou chamar um matemático da corte. Este falou-lhe que nem todos os grãos do mundo seriam suficientes para cumprir o trato realizado.

Este é o primeiro relato de noções exponenciais que se conhece. É sabido que havia outros povos que já conheciam o modelo, mas o conto é o registro antigo mais conhecido.

Trata-se de uma simples história que poderia ser abordada para motivar o ensino do assunto. Decerto, o aluno ficaria muito mais curioso e atento às explicações, já que estaria ouvindo uma narrativa ocorrida no passado, englobando o assunto que será estudado logo a seguir.

Por meio deste simples exemplo, tenta-se mostrar que é possível realizar uma abordagem de conteúdos exponenciais com uma natureza aplicada e voltada para os problemas diários e de outras áreas do conhecimento.

A intenção deste trabalho é retratar a importância do conteúdo matemático exposto através de aplicações cotidianas e curiosidades rotineiras. Portanto, serão mostradas algumas das principais aplicações e curiosidades que envolvem o assunto de funções exponenciais. Existem diversas aplicações bem interessantes da teoria de funções exponenciais que podem ser aplicadas no Ensino Médio, inclusive referenciando outras disciplinas além da Matemática.

\section{Aplicações cotidianas de funções exponenciais}

Este artigo é baseado em dois trabalhos de conclusão do PROFMAT, cujos temas serão inicialmente omitidos nesta versão do artigo para evitar identificação dos autores. Essas dissertações possuem um grande viés pedagógico, e objetivam impactar o ensino nas escolas, mostrando aos docentes como a contextualização pode ajudar o docente em sala de aula. Nelas são propostas sequências didáticas com a exibição de aplicações de funções exponenciais em sala de aula se antecipando ao conteúdo propriamente dito, despertando interesse no discente e mostrando que antes do modelo matemático vem a situação real, cotidiana. Para 
subsidiar os professores, foram apresentadas nestes trabalhos diversas aplicações de funções exponenciais. Foi feita uma seleção das mais interessantes para serem aqui expostas.

\subsection{Desintegração radioativa}

Os átomos de uma substância radioativa (como o rádio e o urânio, por exemplo) tendem a se desintegrar, emitindo partículas e transformando-se noutra substância. As partículas emitidas não alteram consideravelmente a massa total do corpo mas, com o passar do tempo, a quantidade da substância original diminui (aumentando, consequentemente, a massa da nova substância transformada). Isto ocorre de tal modo que, em cada instante, a quantidade de matéria que se está desintegrando naquele momento é proporcional à massa da substância que ainda resta.

Assim sendo, se denominarmos de meia-vida de uma substância radioativa o tempo necessário para que se desintegre a metade da massa de um corpo formado por aquela substância, constatamos que a meia-vida é um número intrinsecamente associado a cada substância radioativa: o tempo necessário para reduzir à metade a radioatividade de uma tonelada de urânio é igual ao tempo que leva um grama da mesma substância para ter sua metade desintegrada. A propósito, como exemplo, os vários isótopos do urânio têm meia-vida da ordem de $10^{9}$ anos. Enquanto isso, a meia-vida do rádio 224 é de 3 dias e 15 horas.

De um modo geral, se designarmos por $m=m(t)$ a massa da substância radioativa presente no corpo no instante $t$, verifica-se que $m$ é uma função decrescente de $t$ e, além disso, a perda relativa $\frac{m(t+h)-m(t)}{m(t)}$, ocorrida após o decurso do tempo $h$, depende apenas de $h$ e não do instante inicial $t$, ou seja, da massa $m(t)$ existente naquela ocasião.

Outra vez, constatamos a necessidade de uma função real de variável $m: \mathbb{R} \rightarrow \mathbb{R}$, que seja monótona injetiva (desta vez, decrescente) e tal que a variação relativa $\frac{m(t+h)-m(t)}{m(t)}$ dependa apenas de $h$. Ou, equivalentemente, que a razão $\frac{m(t+h)-m(t)}{m(t)}$ não dependa de $t$ mas somente de $h$.

Se aplicarmos o Teorema de Caracterização de Funções do tipo Exponencial, concluiremos que a função que representa a massa da substância é deste tipo, ou seja, $m(t)=m_{0} \cdot a^{t}$, onde $m_{0}$ é a massa inicial da substância e $a$ é o fator de decaimento, sendo $0<a<1$.

Vamos dar um exemplo genérico de como encontrar esta função exponencial que representa a massa de uma substância $\mathrm{X}$ no instante $t$, dado que o tempo de meia-vida dessa substância é $t_{1 / 2}$, ou seja, a massa desta substância se reduz à metade após $t_{1 / 2}$ unidades de tempo. Logo, se a massa inicial da substância é $m_{0}$, após decorridos $t_{1 / 2}$ unidades de tempo, a massa será igual a $\frac{m_{0}}{2}$. Analisando a fórmula genérica e utilizando estes valores, temos:

$$
\begin{aligned}
& m(t)=m_{0} \cdot a^{t} \Rightarrow \frac{m_{0}}{2}=m_{0} \cdot a^{t_{1 / 2}} \Rightarrow \frac{1}{2}=a^{t_{1 / 2}} \Rightarrow a=\left(\frac{1}{2}\right)^{\frac{1}{t_{1 / 2}}} \\
& \text { Portanto, a função exponencial encontrada é: } m(t)=m_{0} \cdot a^{t}=m_{0} \cdot\left(\frac{1}{2}\right)^{\frac{t}{t_{1 / 2}}}
\end{aligned}
$$

\subsection{Aplicação de capital a juros fixos}

Como já foi citado no início deste capítulo, a função que expressa a variação do capital, quando aplicado por um período do tempo é do tipo exponencial, isto é, é da forma $c(t)=$ 
Revista Ciências Exatas e Naturais, Vol.19, nº.2, Jul/Dez, 2017

$c_{0} \cdot a^{t}$, onde $c(t)$ expressa o capital no instante $t$ e $c_{0}$ é considerado o fator de aumento do capital. Neste caso, o fator de aumento $a$ é igual a $(1+i)$, onde $i$ é chamado de taxa de juros. Para exemplificar, considere um capital inicial de $\mathbf{R} \$ 2000,00$ aplicado a uma taxa fixa de juros de $2 \%$ ao mês. Portanto, a função que representa o capital no instante $t$, em meses, é dada por:

$$
c_{0} \cdot(1+i)^{t}=2000 \cdot(1+0,02)^{t}=2000 \cdot(1,02)^{t}
$$

Para um quadrimestre, isto é, para um $t=4$, a título de exemplo, temos:

$$
c_{0} \cdot(1+i)^{4}=2000 \cdot(1+0,02)^{4}=2000 \cdot(1,02)^{4} \approx 2164,86
$$

Antes de passarmos à próxima aplicação, tentaremos realizar uma distinção entre juros simples e juros compostos. Em vez de procurarmos definições rígidas e financeiras, vamos à citação do livro de Eli Maor: [3]

"Juro é a remuneração que se paga por tomar dinheiro emprestado, ou que se recebe por emprestá-lo. Usualmente é um percentual do dinheiro que se tomou ou emprestou. Juro simples é o dinheiro pago ou recebido pela quantia original, e que permanece o mesmo em cada prestação, ou seja, se um banco cobra $20 \%$ ao ano de juros simples sobre um empréstimo de cem libras, então, um ano depois, a divida é de 120 libras, depois de dois anos é de 140 libras, depois de três anos é de 160 libras e assim por diante. Com juro composto, no entanto, cada pagamento é uma proporção do total composto, ou acumulado. O dinheiro que se deve dos juros vai alimentar o "pote". Assim, se um banco cobra 20\% de juros compostos, um dívida de 100 libras será de 120 libras após um ano, de 144 libras depois de dois, de 172,80 libras depois de três."

Como o trabalho destina-se a motivar o estudo das funções exponenciais e, em sentido mais strictu, a funções exponencial natural, deixa-se uma citação bem interessante de Maor [3], que explica muito sobre o mundo que vivemos:

"Quem empresta dinheiro tem preferido os juros compostos aos simples ao longo de toda a história conhecida. Inclusive, num dos primeiros problemas da literatura matemática, numa tabuleta de barro mesopotâmica de 1700 a.C., a pergunta é quanto tempo levaria para que uma quantia dobrasse de valor a um juro composto de $20 \%$ ao ano. Um dos motivos que fazem a atividade bancária ser tão lucrativa é que o juro composto faz crescer a divida, ou o empréstimo, exponencialmente, o que vale dizer que você pode acabar pagando, ou ganhando, quantias exorbitantes em pouco tempo. Os romanos condenaram o juro composto como a pior forma de usura. No Alcorão, é declarado um pecado. Não obstante, o sistema financeiro moderno baseia-se nessa prática. É como os nossos saldos devedores, faturas de cartão de crédito e pagamentos de hipotecas são calculados. O juro composto tem sido o principal catalisador do crescimento econômico desde o início da civilização."

Infelizmente, no nosso Ensino Básico, não se tem a devida preocupação com Educação Financeira. $\mathrm{O}$ assunto está intimamente ligado aos modelos exponenciais abordados no presente trabalho. Conforme citado acima, instituições financeiras praticam o emprego de composições exponenciais, por serem mais lucrativas ao sistema. Ensina-se porcentagem, função afim, função logarítmica, função exponencial e outros assuntos sem relacioná-los com a realidade financeira que nos cerca. Atualmente, falar-se em ser educado financeiramente resume-se apenas a ter um consumo responsável, controlar gastos e caderneta de poupança. A matéria é muito mais abrangente que isso.

Assim, novamente com o intuito de despertar a completa atenção do discente, vamos a um exemplo, o qual é imperioso que seja tratado em sala de aula. Refere-se como o sistema financeiro britânico se comporta ao oferecer serviços aos seus consumidores. Certamente, 
muitos consumidores ficam bastante confusos quando observam determinados financiamentos com as mais variadas modalidade de capitalização. Vejamos como a Inglaterra tenta ser um pouco mais clara, neste ponto:

"Isso porque as instituições financeiras britânicas são obrigadas por lei a declarar a taxa de juro composto contínua em cada produto que vendem, qualquer que seja a sua opção de creditar mensalmente, bisanualmente, anualmente ou o que for. Digamos que um banco ofereça uma conta de depósito que remunera $15 \%$ ao ano, composto em um crédito anual, o que significa que depois de um ano um depósito de cem libras terá aumentado para 115 libras. Se esses 15\% forem compostos continuamente, após mais um ano aumentará para $£ 100 . e^{\frac{15}{100}}$, o que resulta em 116,18

libras, revelando uma taxa de juros de 16,18\%. O banco é obrigado por lei a declarar que essa

conta de depósito rende 16,18\%. Embora pareça estranho que um banco declare um valor não usado na prática, isso foi introduzido para que os clientes possam comparar coisa com coisa. Uma conta que credita mensalmente e uma que credita anualmente serão avaliadas por sua taxa composta contínua. Como quase todo produto financeiro envolve juros compostos, e cada cálculo de composição contínua vai dar num e, a constante exponencial é o número do qual depende todo o sistema financeiro."

(Bellos [3])

\subsection{O caso do paraquedas}

Esta aplicação deve ser abordada com bastante cuidado pelo professor, pois apesar de interdisciplinar (envolve Matemática e Física), ela também engloba conhecimentos que fogem ao conteúdo do Ensino Médio. Todavia, se usada adequadamente, agregará ao aluno algumas noções de força, de resistência do ar e de como ocorre a redução de velocidade do paraquedista.

Analisemos, então, o caso de um homem que salta de paraquedas. As forças que atuam sobre ele são: a força peso, na direção vertical com sentido para baixo e a força de resistência do ar, que é proporcional à velocidade do corpo, também vertical e com sentido contrário ao da força peso. De acordo com a Segunda Lei de Newton, o somatório das forças é igual ao produto da massa pela aceleração. Logo, sendo $m$ a massa do paraquedista, $a$ sua aceleração, $v$ a sua velocidade, $k$ a constante de proporcionalidade da força de resistência do $\operatorname{ar}\left(F_{a r}=k v\right)$ e $g$ a aceleração da gravidade, temos:

$$
m a=m g-k v
$$

Como a função aceleração é a função derivada da função velocidade em relação ao tempo, podemos resolver essa equação diferencial ordinária e encontrar uma expressão para a velocidade. Obviamente, este assunto foge ao escopo do Ensino Médio e, por isso, o professor deve se ater a analisar a equação do balanço de forças e, em seguida, exibir o resultado final, a fim de mostrar aos alunos que a velocidade cai exponencialmente quando o corpo sofre a resistência do ar. A expressão final da velocidade em função do tempo é:

$$
v(t)=\frac{m g}{k}+C \cdot e^{-\frac{k t}{m}}
$$

onde $C$ é uma constante e $e$ é a constante neperiana. Ainda, com uma manipulação algébrica para não ter a massa do saltador na expressão, vale dizer:

$$
v=\frac{g}{a}\left(1-e^{-a t}\right)+v_{0} e^{-a t}
$$


$\operatorname{com} a=\frac{k}{m} \cdot 1$

Observando a equação 1, pode-se ter conclusões interessantes e importantes: se o paraquedista comandar (termo utilizado para o acionamento do paraquedas, quando isso é possível, já que existem paraquedas que são acionados pela ação da gravidade quando a pessoa salta do aerotransporte) o seu equipamento assim que sair do avião, pode-se dizer que $v_{0}=0$, fazendo com que o último termo da equação 1 seja eliminado.

Ainda, se ele cair livremente, ou em linguagem técnica, entrar em queda-livre, antes de comandar o seu paraquedas, sua velocidade $v_{0}$ aumentará bastante, porém o seu efeito diminui exponencialmente conforme o avançar do tempo. Isso é fato pois, se $t \rightarrow \infty$, a expressão $e^{-a t}$ tende a zero e a velocidade limite, chamada, por exemplo, de $v_{\infty}$ será igual a $\frac{g}{a}$ ou ainda, $v_{\infty}=\frac{m g}{k}$ será atingida.

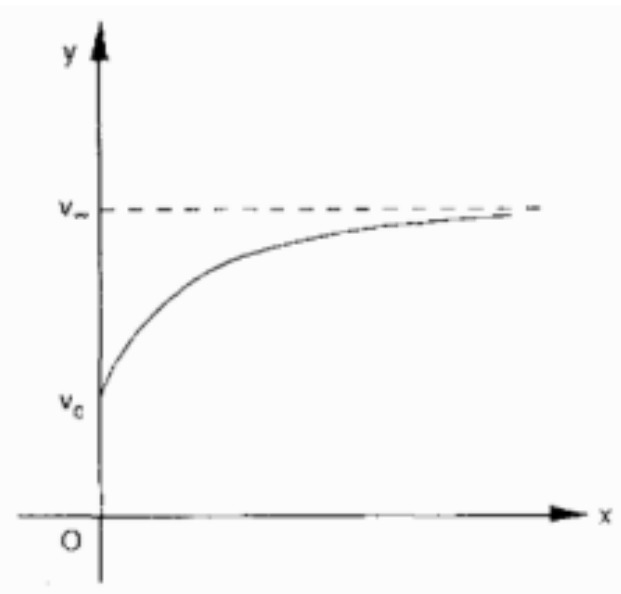

Figura 1. Atingimento da velocidade limite $v_{\infty}$ do salto de paraquedas Fonte: Maor, 2003. [4]

E isso é o mais interessante: se a velocidade limite é atingida independente do $v_{0}$ inicial do acionamento do paraquedas, dependendo apenas do peso do saltador e do coeficiente de resistência, podemos concluir que tal fato é o que permite que o pouso seja seguro, chegando ao solo com uma velocidade compatível. Mas é claro: deve-se acionar o paraquedas!

\subsection{Percepções a estímulos físicos - Experiência sonora}

Assim como a anterior, a aplicação deve ser usada com muito cuidado. Alguns conceitos mais avançados podem confundir a construção do raciocínio e do conhecimento do estudante do Ensino Médio. Todavia, trata-se de algo muito interessante de ser levado ao conhecimento.

O fisiologista alemão Ernst Heinrich Weber (1975-1878) ${ }^{2}$ desenvolveu um teste, obtido por intermédio de vários experimentos, que seria capaz de quantificar a resposta humana a diversos estímulos físicos recebidos ou aplicados. A generalização deste teste para todos os sentidos foi recepcionada pelo médico alemão Gustav Theodor Fechner (1801-1887) e ficou

\footnotetext{
${ }^{1}$ A demonstração detalhada poderá ser obtida na obra e: a história de um número, de Eli Maor.

${ }^{2}$ Ernst Heinrich Weber (Wittenberg, 24 de junho de $1795-26$ de janeiro de 1878) foi um médico alemão e é considerado fundador da psicologia experimental.
} 
conhecida como a lei de Weber-Fechner. Para ilustrar melhor, um dos experimentos foi aplicado em um homem totalmente vendado que segurava um determinado peso. Assim, outros pesos menores eram acrescentados gradativamente e a cobaia humana deveria responder quando percebia uma alteração de peso pela primeira vez [4].

Após inúmeros experimentos desta natureza e em todos os sentidos sensoriais, Weber pode concluir que a resposta ao estímulo era proporcional ao aumento relativo, e não ao aumento absoluto. Explicando melhor: se um homem estivesse segurando um peso de 20 quilogramas e pudesse sentir um aumento de peso quando fosse introduzido um peso de 2 quilogramas, quando ele estivesse com um peso de 40 quilogramas, só sentiria o aumento a partir de 4 quilogramas, que corresponde a $10 \%$ de aumento do peso em ambos os casos.

Conforme Maor [4], em modo matemático, se pode escrever:

$$
d s=k \frac{d W}{W},
$$

onde $d s$ é o aumento perceptível (seria a condição limite, o menor aumento de peso que pudesse ser percebido), $d W$ é o aumento de peso correspondente, $W$ o peso já usado com a cobaia e $k$ uma constante de proporcionalidade.

A lei de Weber-Fechner, como está em 2, é uma equação diferencial. Devemos ter muito cuidado ao apresentar tal conteúdo no Ensino Médio: aqui, não se deve adentrar em explicações detalhadas sobre como obter a função derivada ou a antiderivada, bastando apenas informar o que foi feito. Isso não prejudicará o aprendizado, tampouco o exemplo trazido.

Então, integrando 2, tem-se:

$$
s=k \ln W+C,
$$

com $C$ sendo uma constante de integração. Conforme [4], fazendo $W_{0}$ o mais baixo nível de estímulo físico, isto é, o nível limite, teremos, $s=0$ quando $W=W_{0}$, obtendo $C=-k \ln W_{0}$. Colocando na equação 3 e usando as propriedades de logaritmos, tem-se:

$$
s=k \ln \frac{W}{W_{0}},
$$

mostrando que a resposta segue um padrão logarítmico (função inversa da exponencial). Trocando em miúdos: se o estímulo aumentar em taxa constante, isto é, em progressão geométrica, a resposta ao estímulo aumentará em proporções iguais.

Apesar da contestação dos experimentos, já que a receptividade humana é uma questão subjetiva, os testes se aplicam muito bem à sensação de volume, dada a capacidade de percepção da audição humana.

"Quando a lei de Weber-Fechner é aplicada à tonalidade, ela diz que intervalos musicais iguais (aumentos de tonalidade) correspondem a aumentos fracionais iguais na frequência. Daí os intervalos musicais corresponderem a relações de frequência. Por exemplo, uma oitava corresponde à proporção 2:1 na frequência, uma quinta à proporção 3:2, uma quarta a 4:3 e assim por diante. Quando ouvimos uma série de notas separadas por oitavas, sua frequência na verdade aumenta em uma progressão 1, 2, 4, 8, e assim por diante."

(Maior [4]) 
Revista Ciências Exatas e Naturais, Vol.19, nº.2, Jul/Dez, 2017

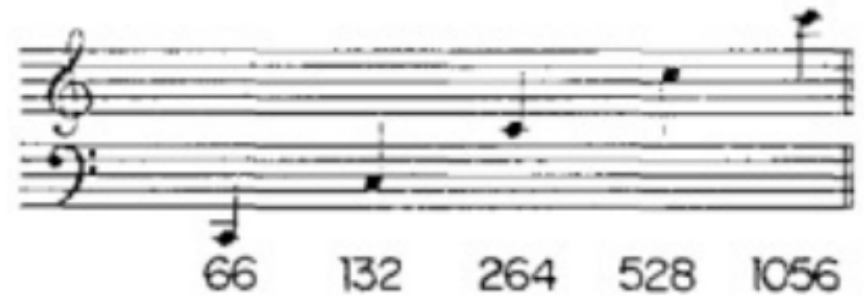

Figura 2. Notas musicais separadas em intervalos iguais correspondem a frequências em uma progressão geométrica

Fonte: Maor, 2003 [4].

Isso nos permite concluir que as pautas onde as notas musicais são escritas é, na verdade, uma escala logarítmica, na qual a distância vertical, chamada de tom, é proporcional ao logaritmo da frequência. [4]

\subsection{A corrente suspensa}

O problema da corrente suspensa envolve o número $e$ e a função $f(x)=e^{x}$. Trata-se da seguinte indagação: qual é a curva formada por um fio pendente, livremente suspenso por dois pontos fixos, assumindo que o fio é flexivel em toda a sua extensão e possui uma espessura constante? (entende-se como densidade linear uniforme). Tal problemática foi exposta por Jakob Bernoulli em maio de 1690 na Acta eruditorum, revista esta que o próprio havia fundado oito anos antes.

Acerca das respostas a este questionamento, citamos [4]:

"A história desse famoso problema é bem semelhante à da braquistócrona e quase os mesmos personagens tomaram parte nela. Galileu já tinha demonstrado interesse e imaginara que a curva

era uma parábola. Aos olhos, a corrente suspensa certamente se parece com uma parábola. Mas

Christian Huygens, o prolifico cientista holandês, cujo papel na história tem sido um tanto subestimado (sem dúvidas porque viveu entre as eras de Kepler e Galileu antes dele, e Newton e Leibniz depois), provou que a catenária não podia ser uma parábola."

Houve outras respostas para o problema evidenciado. Em 1691, a publicação Acta expôs três soluções corretas para a questão: uma por Leibniz; outra por Huygens; e por Johann Bernoulli.

Fazendo uma nota histórica, na verdade, uma curiosidade acerca da família Bernoulli. Jakob e Johann eram rivais acirrados. Mesmo sendo irmãos, a competição pelas descobertas matemáticas eram muito maiores que a afeição familiar. Rivalizaram por toda a vida pelas respostas e soluções dos principais desafios matemáticos da época, a ponto de ficarem sem se falar durante um longo período de tempo. Comprovando o exposto, ainda em [4]:

"Johann acrescentou que, das duas curvas, a parábola é algébrica enquanto a catenária é transcendental. Impetuoso como sempre, concluiu: "O senhor conhece a disposição do meu irmão.

Ele não hesitaria, se pudesse fazê-lo honestamente, em tirar-me a honra de ser o primeiro a resolvê-lo, em vez de me deixar tomar parte - e muito menos me cederia o lugar, se já fosse meu".

A notoriedade dos Bernoullis de brigarem entre si - e com os outros - não diminuíra nada com a passagem do tempo."

A catenária é a curva cuja equação é dada por: 


$$
y=\frac{e^{a x}+e^{-a x}}{2 a}
$$

para a uma constante cujo valor é relacionado aos parâmetros físicos da corrente, como densidade linear e tensão com a qual ela é segura.

Quanto à equação acima vale expressar:

"Devemos mencionar que a equação da catenária não foi apresentada originalmente na forma acima. O número e ainda não tinha um símbolo especial, e a função exponencial não era considerada função independente e sim um inverso da função logarítmica."

Para $a=1$, podemos construir o gráfico por intermédio dos gráficos de $e^{x}$ e de $e^{-x}$ no mesmo sistema de coordenadas: trata-se de realizar, para cada ponto $x$ do domínio, a soma $e^{x}+e^{-x}$ e, na sequência, dividir o resultado por 2. Esse será a ordenada de cada ponto $x$ do domínio.

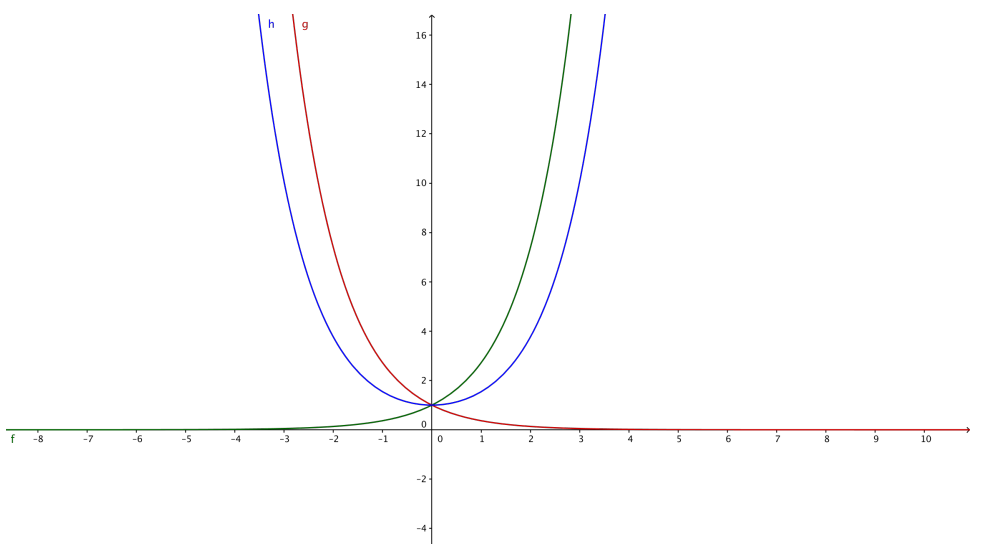

Figura 3. Gráfico de $e^{x}, e^{-x}$, e da catenária para $a=1$

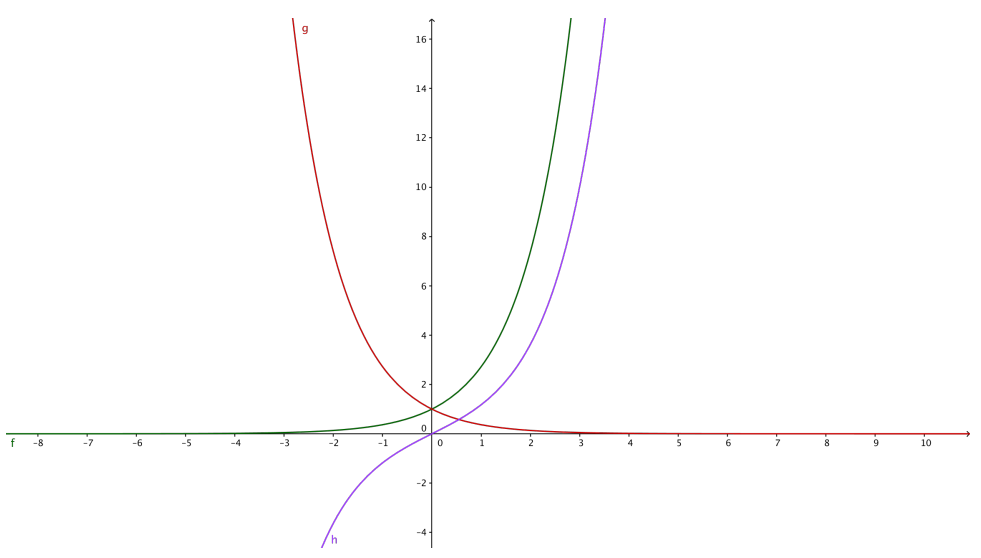

Figura 4. Gráfico de $\frac{e^{x}-e^{-x}}{2}$ 
Revista Ciências Exatas e Naturais, Vol.19, nº.2, Jul/Dez, 2017

Considerando as equações dos dois gráficos plotados acima, quando em função de $x$, são muito semelhantes às equações das funções circulares cosseno e seno ( sen e cos). Essas similaridades foram notadas por Vincenzo Ricatti $(1707-1775)^{3}$ que introduziu as notações de seno e cosseno hiperbólicos ( $\sinh$ e cosh), a saber:

$$
\sinh \phi=\frac{e^{x}+e^{-x}}{2} ; \cosh \phi=\frac{e^{x}+e^{-x}}{2}
$$

O italiano demonstrou que é válida a igualdade

$$
\cosh ^{2} \phi-\sinh ^{2} \phi=1
$$

que, excetuando-se pelo sinal negativo, é igual à identidade trigonométrica consagrada no Ensino Médio:

$$
\cos ^{2} \phi+\operatorname{sen}^{2} \phi=1
$$

Vale aqui uma analogia importante a ser trabalhada com os alunos do Ensino Médio: comparar a identidade trigonométrica consagrada, representada pela equação 8 e a igualdade hiperbólica da equação 7 com as equações de um círculo de raio unitário centrado na origem e de uma hipérbole equilátera de equação $x^{2}-y^{2}=1$, respectivamente.

A notação de Rivatto ficou consagrada para cosh $\phi$ como cosseno hiperbólico de $\phi$ e seno hiperbólico de $\phi$ como $\sinh \phi$. Através das propriedades especiais das funções $e^{x}$ e $e^{-x}$, a identidade da equação 7 pode ser demonstrada elevando-se ao quadrado ambos os lados das equações 6 e usando as identidades $e^{x} \cdot e^{y}=e^{x+y}$ e $e^{0}=1$.

\section{Uma conversa com os professores do Ensino Médio}

Na época da elaboração dos já citados trabalhos de conclusão de curso, com o objetivo de verificar como estava o ensino de funções exponenciais nas escolas de Ensino Médio, foi feita uma pesquisa entre diversos docentes, tanto pela Internet quanto presencialmente. Uma das perguntas feitas, cuja temática está sendo abordada neste artigo, é a seguinte: Você apresenta em sala possiveis aplicações para funções exponenciais? Caso positivo, cite alguns exemplos.

Nesta pergunta, todos os professores citaram os casos clássicos como: matemática financeira (juros compostos), crescimento populacional, decaimento radioativo, ingestão de medicações. Casos menos convencionais também foram citados: distribuição de Poisson (aplicações em teoria das filas; filas de banco; filas de buffer de um roteador; filas de paginação de um sistema operacional, entre outros), ruído gaussiano branco, curvas $P V^{\alpha}$ do gás ideal.

Seguem algumas respostas interessantes a esta pergunta:

1. Sim, mostro que elas representam uma progressão geométrica e cito os juros compostos em matemática financeira. São conteúdos que possuem diversas aplicações na literatura

\footnotetext{
${ }^{3}$ Vincenzo Riccati (Castelfranco Veneto, 11 de janeiro de 1707 - Treviso, 17 de janeiro de 1775 ) foi um matemático e físico italiano. Irmão de Giordano Riccati, foi o segundo filho de Jacopo Francesco Riccati. Riccati continuou a obra de seu pai em análise matemática, especialmente no campo das equações diferenciais e física. A equação de Riccati é denominada em memória de seu pai.
} 
2. Sim. Como exemplos cito o sistema de juros compostos, a decomposição de determinadas substâncias e o crescimento de determinados seres vivos microscópicos, como as bactérias.

3. Sim, falo sobre o decaimento radioativo e a escala Richter para intensidade de terremotos.

4. Sim, sempre é bom mostrar exemplos. Costumo falar de crescimento de populações na ausência de predadores naturais (como em algumas bactérias). Também menciono o crescimento da população mundial. Se der tempo falo de poupança também.

5. Sim, falo de diversas aplicações: Ruído gaussiano branco, através da função exponencial de Gauss; probabilidade, através da distribuição de Poisson (aplicações em teoria das filas: filas de banco, filas de buffer de um roteador, filas de paginação de um sistema operacional).

Essas respostas demonstram a preocupação desses professores em conectar a realidade à teoria, o que é fundamental para auxiliar num melhor processo de aprendizagem por parte do discente. É bastante motivador perceber que já existe essa preocupação em sala de aula, e este trabalho intenta municiar os professores de mais possibilidades de aplicações práticas para exibir em sala.

\section{Conclusões}

Procurou-se com este trabalho, sob um enfoque mais amplo, mostrar que o ensino através de uma perspectiva aplicada pode obter melhores resultados quanto ao processo de ensino-aprendizagem do aluno. Através de uma minuciosa revisão de literatura, tentou-se corroborar o que foi defendido ao longo desta jornada. Os Parâmetros Curriculares Nacionais foram os norteadores deste estudo, confirmando que já há um preocupação antiga em se ensinar Matemática de forma mais natural e aplicada, sem abandonar o formalismo necessário à ciência. Buscou-se trazer exemplos interessantes, como por exemplo a abertura de paraquedas modelada por uma função tipo exponencial natural, permitindo concluir que o saltador sempre chegará com uma velocidade de pouso compatível, impedindo acidentes. A pequena contribuição que este artigo almeja é fazer com que o aluno do Ensino Médio se interesse mais pela Matemática ao aprender o conteúdo de funções exponenciais, já que este possui uma enorme gama de aplicações que conseguem despertar um maior interesse do discente. A Matemática tem sido há muito tempo vista como vilã pelos estudantes, repleta de conteúdos teóricos intermináveis e exercícios repetitivos e sem correspondência com a realidade. Portanto, algo precisa ser mudado na forma como a mesma é ministrada nas milhares de salas de aula espalhadas pelo nosso país.

\section{Referências}

[1] BRASIL; Parâmetros Curriculares Nacionais - Ensino Médio, 1998

[2] BASSANEZI; Ensino-aprendizagem com modelagem matemática: uma nova estratégia, Contexto, 2002

[3] BELLOS, A; Alex através do espelho: como a vida reflete os números e como os números refletem a vida, Companhia das Letras, 2015. 
Revista Ciências Exatas e Naturais, Vol.19, nº .2, Jul/Dez, 2017

[4] MAOR, E. e: a história de um Número. Record, 2003. 